of burns centres, first in Britain and then throughout the world, has allowed more concentrated attacks to be made on the multitude of problems associated with the treatment of the severely burned patient. These burns centres, by attracting such patients, have disclosed the vast range of metabolic problems which are little understood, and have produced more interest and co-operation between members of different specialties. It is being increasingly recognized that the anaesthetist has an important role in the solution of these problems. The skilled use of general anaesthesia, and the use of suitable analgesics for the relief of pain during burns dressings, are receiving more attention from anaesthetists interested in the complex psychological and metabolic derangements to which the severely burnt patient is subject. Nevertheless, it is regrettable that only very few burns centres in the world have the services of a full-time anaesthetist.

Evidence of the anaesthetists' growing concern about the problems they meet in the treatment of burnt patients was shown by the success of a recent symposium. It was held at the Queen Victoria Hospital, East Grinstead, in October 1971, and its proceedings have now been published. ${ }^{1}$ It considered "The Place of the Anaesthetist in the Treatment of the Burnt Patient." The meeting was apparently the first of its kind in any country and was attended mainly by anaesthetists (together with a small number of physicians and surgeons) from Britain, but with participants from Australia, Belgium, Canada, Holland, and Jugoslavia. Its proceedings show that a more rational approach to treatment has become possible because of growing success in the control of pain.

The symposium was divided into two sessions. The first of these was devoted primarily to the problem of the control of pain of the burns dressing. Being a pioneer meeting, the meaning of the term "burns dressing" had to be discussed, for it is subiect to many interpretations, ranging in one hospital from the removal of bandages and underlying dressings to extencive surgical procedures such as the taking of solit skin grafts. But uniformity of definition is proving difficult to obtain. The first Daper reviewed the history of analgesic methods used for the burnt patient. The number of remedies invoked over the centuries are a testimony to the confusion and loose thinking associated with this problem. It would appear that not until the late 1940s were techniques evolved which could offer effective analgecia without disturbing the patient's feeding pattern. ${ }^{2} 3$ At this time also it began to be aporeciated that the complete control of pain, as well as being an obvious goal in itself, also contributed handsomely to the general physical and psychological wellbeing of the patient.

The effectiveness of "neuroleptanalgesia"- a combination of droperidol and phenoperidine-in the control of pain, was reported in 1966.4 This technique, modified by the addition of Entonox, was reported on by P. J. F. Baskett in this symoosium. A further procedure was reported on by K. J. Packer-a continuation of previously described work with methoxyfluorane. ${ }^{5}$ This rebort drew attention to recent advances - namely, ranid recovery after the administration of the drug, total elimination of the pre- and postoperative fasting, the absence of vomiting, and some postoperative analgesia. This speaker underlined the ultimate aim of the treatment of the burnt patient-c"To return an economically indenendent individual to the community." Both this speaker and others voiced their concern at the reports that methoxyfluorane had a nephrotoxic effect, ${ }^{6}$ for if they are con- firmed they will probably lead to the removal of an unequalled inhalation drug from the anaesthetists' armamentarium. However, it would appear that the nephrotoxic effect of methoxyfluorane is related to the dose used, to the frequency of its administration, and to the simultaneous use of other drugs-for example, tetracycline. ${ }^{7}$

The second session of the symposium was devoted to reports and discussion of the complex biochemical changes which occur in the burnt patient. They are assuming greater importance as the surgical problems associated with the burn wound are being overcome. A physician specializing in this field described her experience in treating these metabolic disturbances and outlined future trends and problems. The final papers were on the general as well as the specific problems of anaesthesia in both the burnt child and the burnt adult. It was reassuring to hear reiterated the warnings about administering succinylcholine to burnt patients and to learn of the continued usefulness of wellestablished agents such as trichlorethylene. Finally, the use of ketamine both as an analgesic and an anaesthetic for full surgical procedures was discussed, including the terrifying dreams it may cause.

Much useful information was disseminated at this symposium, and its aims were largely fulfilled. The nature of the problems were clarified, and a focal point for future discussions established. A second symposium is to be held in Edinburgh in 1973, and it is hoped that further support by those interested in the treatment of the burnt patient will be forthcoming.

1 Postgraduate Medical 7ournal, 1972, 48, 123.

2 Gordon. R. A., Canadian Medical Association fournal, 1943, 49, 478. Visser, E. R., and Farrow. A. B., Anesthesia and Analgesia-Current Researches, $1959,38,301$.

4 Smith. B. G., and Hollis, D. A., British founal of Anaesthesia, $1966,38,471$.

Packer. K. J., and Titel, J. H., British fournal of Anaesthesia, 1969,

6 Mazze, R. I., Shue, G. L., and Tackson, S. H., fournal of the American Medical Association, 1971, 216, 278.

Proctor. A. E., and Barton, S. L., British Medical fournal, 1971, 4,661 .

\section{Mothering the Baby}

Two years ago a leading article in this journal ${ }^{1}$ stated: "In Britain it seems natural and normal for a mother in a maternity hospital to have her full-term baby not in a nursery but at her bedside, so that she can admire him, gloat over him, show him off, and display his beauty, pick him up, cuddle him, and feed him as soon as he cries from hunger." But American journals continue to publish studies of "rooming in" and of the effect of handling the newborn baby. In a Californian study ${ }^{2}$ in which 41 mothers were allowed to handle and later feed their babies all but two mothers thought that the idea was a good one.

Now a Cleveland group ${ }^{3}$ has set out to determine whether present practices with regard to the care of the newborn may influence later behaviour. The Cleveland workers wrote that "In most nurseries in the United States, however, even full-term mothers are separated from their infants for a short, but possibly important time." They allowed 14 mothers of normal full-term babies, acting as controls, to have "traditional contact with their infants: a glimpse of the baby shortly after birth, brief contact and identification at six to 12 hours, and then visits for 20 to 30 minutes every 
four hours for bottle feedings." The experimental group of 14 mothers were in addition "given their nude babies, with a heat panel overhead, for one hour within the first three hours after birth, and also five extra hours of contact each afternoon of the three days after delivery."

To determine whether this additional time with the infant altered later behaviour they brought the mothers back 28 to 32 days after delivery for a standardized interview, for observation when the infant was being examined, and for a filmed study of the mother feeding her baby. Mothers were asked, "When the baby cries and has been fed, and the diapers are dry, what do you do?" (Score of 0 for "letting the baby cry it out," 3 for "picking up the baby every time.") Another question was, "Have you been out since the baby was born, and who sat?" (Score 0 for "yes" and "if the mother felt good and did not think about her infant while she was out." A score of 3 "if she did not go out or leave the baby with anyone, or if she did go out but thought constantly about the baby.") During the examination of the baby a mother scored 3 if "she was standing by the pediatrician and watching continuously"; a score of 0 if "she remained seated and looked elsewhere." The experimental group, which had more contact with their babies, secured a higher score than the control group.

It is always difficult to know how far the results of animal studies are applicable to human beings. Many studies have shown that separation of the newborn animal from his mother immediately after birth has a bad effect both on the young and on the mother's attitude to her young. ${ }^{4-10}$ For instance, if a newborn kid is separated from his mother for only 15 to 45 minutes after birth and then returned to his mother, she rejects the kid and butts it, refusing to allow it to suckle. ${ }^{11}$ Goats, sheep, and other animals need to lick their young at birth, particularly in the genital area, and failure to do so leads to rejection. Puppies separated from their mothers at birth tend to be less affectionate and more difficult to train. When newborn rats are separated from their mothers at birth and then returned, the mothers nurse them less and do not bother to "retrieve" them-that is, to bring them back to the nest if they wander away or are placed at a distance away. It seems that continuous association with actively suckling young is necessary for the development of normal maternal behaviour, and if mothers are deprived of it their quality of mothering suffers.

Mothers in a maternity unit sometimes say that they feel the urge to have skin contact with the baby immediately he has been born. Some want to put him to the breast immediately. Some feel that it is important that they should be fully conscious at the time of delivery and not under an anaesthetic. Human studies of the effect of such instincts or of interference with them are fraught with difficulties because of all the variables involved, but in the present state of our knowledge it is wise to respect the instincts. It would certainly seem wrong to prevent a mother from handling her baby if she wants to do so. After all, the baby is hers, she has nurtured him for some nine months, and it seems unnatural to separate mother and child unless the child is ill or is a small premature baby needing special care. Even then $i_{i}$ is the practice of many paediatricians in Britain to encourage mothers to handle their premature babies and to feed them and clean them up, because separation of mother and baby might harm the mother-child relationship. A particular problem arises when babies are born with a handicap, such as spina bifida or difficult metabolic problems. It would be sensible to try to reduce to a minimum the duration of these babies' stay in hospital and to try to encourage contact between mother and child. When a child is eventually discharged home after a long stay in hospital from birth because of a major handicap or some obscure error of metabolism, it is not uncommon for the mother to reject her child.

We need to pay more thought to anything which severs the natural bond between the newborn and his motherbottle feeding instead of breast feeding, separation of the baby by putting him in a nursery, discouragement of the mother from picking the baby up when he cries or feeding him when he is hungry-or anything which prevents her enjoying him or his enjoying her.

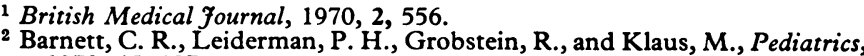
1970, 45, 197.

3 Klaus, M. H., et al., New England fournal of Medicine, 1972, 286, 460.

4 Vaughan, V. C., Fournal of the American Medical Association, 1966, 198, 45.

${ }^{5}$ Rheingold, H. L., in Maternal Behavior in Mammals. New York, John Wiley, 1963.

- Denenberg, V. H., Stimulation in Early Infancy, ed. A. Ambrose. London, Academic Press, 1969

'Hersher, L., Richmond, J. B., and Moore, A. U., in Maternal Behavior in Mammals. New York, John Wiley, 1963.

${ }^{8}$ Ambrose, A., in Foundations of Child Psychiatry. Oxford, Pergamon, 1968. 9 Harlow, H. F., and Harlow, M. K., in Determinants of Infant Behavior, ed. Foss, B. M., vol. IV. London, Methuen, 1969.

${ }_{10}$ Hersher, L., Moore, A. U., and Richmond, J. B., Science, 1958, 128, 1342.

1 Collias, N. E., Ecology, 1956, 37, 228.
}

\section{Cardiac Biopsy}

Though there has been considerable progress in the diagnosis and investigation of cardiac disease, a group of disorders remain, collectively known as the cardiomyopathies, in which the aetiology and pathological classification await clarification. Knowledge of renal, hepatic, gastrointestinal, and to a lesser extent pulmonary disease has advanced rapidly since the introduction of simple biopsy techniques permitting the correlation of the pathological features with the clinical and metabolic manifestations. Cardiac biopsy has not been so enthusiastically supported, and consequently knowledge of the cardiomyopathies has been based primarily on the clinical and haemodynamic features. Without an understanding of pathogenesis, it is not surprising that treatment has been empirical and generally unsatisfactory. The diagnosis of the cardiomyopathies is often only presumptive during life. The pathological features have until recently been determined solely at necropsy, but this discloses only the final stage in a protracted pathological process, which will have been modified by metabolic alterations during the terminal illness and by post-mortem autolysis.

Several techniques of cardiac biopsy have been described. A biopsy may be taken at the time of open heart surgery, or a small thoracotomy may be electively performed to obtain cardiac tissue. ${ }^{12} \mathrm{~A}$ thoracotomy, however limited in extent, is a major procedure, which though having advantages is unlikely to find a place in the routine assessment of patients with myocardial disease. A variety of percutaneous techniques have been used for cardiac biopsy,,$^{3-6}$ the usual approach being similar to that for left ventricular puncture. ${ }^{7}$ Though relatively free from complications, a percutaneous approach may be frightening for the patient, and the dangers of pneumothorax, cardiac tamponade, and unexplained hypotension are present. ${ }^{8}$ Furthermore, the amount of tissue obtained is often inadequate. During the last decade S. Konno and his colleagues ${ }^{910}$ in Japan have developed an 